ISSN 00156043

\title{
DOCUMENTO
}

\section{Mensaje de Benedicto XVI para la celebración de la Jornada mundial de la Paz}

\section{Combatir la pobreza, construir la paz}

1. También en este año nuevo que comienza, deseo hacer llegar a todos mis mejores deseos de paz, e invitar con este Mensaje a reflexionar sobre el tema: Combatir la pobreza, construir la paz. Mi venerado predecesor Juan Pablo II, en el Mensaje para la Jornada Mundial de la Paz de 1993, subrayó ya las repercusiones negativas que la situación de pobreza de poblaciones enteras acaba teniendo sobre la paz. En efecto, la pobreza se encuentra frecuentemente entre los factores que favorecen o agravan los conflictos, incluidas la contiendas armadas. Estas últimas alimentan a su vez trágicas situaciones de penuria. "Se constata y se hace cada vez más grave en el mundo -escribió Juan Pablo II- otra seria amenaza para la paz: muchas personas, es más, poblaciones enteras viven hoy en condiciones de extrema pobreza. La desigualdad entre ricos y pobres se ha hecho más evidente, incluso en las naciones más desarrolladas económicamente. Se trata de un problema que se plantea a la conciencia de la humanidad, puesto que las condiciones en que se encuentra un gran número de personas son tales que ofenden su dignidad innata y comprometen, por consiguiente, el auténtico y armónico progreso de la comunidad mundial" ${ }^{\prime \prime}$.

2. En este cuadro, combatir la pobreza implica considerar atentamente el fenómeno complejo de la globalización. Esta consideración es importante ya desde el punto de vista metodológico, pues invita a tener en cuenta el fruto de las investigaciones realizadas por los economistas y sociólogos sobre tantos aspectos de la pobre-

\footnotetext{
${ }^{1}$ Mensaje para la Jornada Mundial de la Paz de 1993, 1.
} 
za. Pero la referencia a la globalización debería abarcar también la dimensión espiritual y moral, instando a mirar a los pobres desde la perspectiva de que todos comparten un único proyecto divino, el de la vocación de construir una sola familia en la que todos - personas, pueblos y naciones- se comporten siguiendo los principios de fraternidad y responsabilidad.

En dicha perspectiva se ha de tener una visión amplia y articulada de la pobreza. Si ésta fuese únicamente material, las ciencias sociales, que nos ayudan a medir los fenómenos basándose sobre todo en datos de tipo cuantitativo, serían suficientes para iluminar sus principales características. Sin embargo, sabemos que hay pobrezas inmateriales, que no son consecuencia directa y automática de carencias materiales. Por ejemplo, en las sociedades ricas y desarrolladas existen fenómenos de marginación, pobreza relacional, moral y espiritual: se trata de personas desorientadas interiormente, aquejadas por formas diversas de malestar a pesar de su bienestar económico. Pienso, por una parte, en el llamado "subdesarrollo moral" 2 $y$, por otra, en las consecuencias negativas del "superdesarrollo" ${ }^{3}$. Tampoco olvido que, en las sociedades definidas como "pobres", el crecimiento económico se ve frecuentemente entorpecido por impedimentos culturales, que no permiten utilizar adecuadamente los recursos. De todos modos, es verdad que cualquier forma de pobreza no asumida libremente tiene su raíz en la falta de respeto por la dignidad trascendente de la persona humana. Cuando no se considera al hombre en su vocación integral, y no se respetan las exigencias de una verdadera "ecología humana" ${ }^{4}$, se desencadenan también dinámicas perversas de pobreza, como se pone claramente de manifiesto en algunos aspectos en los cuales me detendré brevemente.

\section{Pobreza e implicaciones morales}

3. La pobreza se pone a menudo en relación con el crecimiento demográfico. Consiguientemente, se están llevando a cabo campañas para reducir la natalidad en el ámbito internacional, incluso con métodos que no respetan la dignidad de la

\footnotetext{
2 PABLO VI, Populorum progressio, 19.

3 JuAn Pablo II, Sollicitudo rei socialis, 28.

${ }^{4}$ Juan Pablo II, Centesimus annus, 38.
} 
mujer ni el derecho de los cónyuges a elegir responsablemente el número de hijos ${ }^{5}$ y, lo que es más grave aún, frecuentemente ni siquiera respetan el derecho a la vida. El exterminio de millones de niños no nacidos en nombre de la lucha contra la pobreza es, en realidad, la eliminación de los seres humanos más pobres. A esto se opone el hecho de que, en 1981, aproximadamente el $40 \%$ de la población mundial estaba por debajo del umbral de la pobreza absoluta, mientras que hoy este porcentaje se ha reducido sustancialmente a la mitad y numerosas poblaciones, caracterizadas, por lo demás, por un notable incremento demográfico, han salido de la pobreza. El dato apenas mencionado muestra claramente que habría recursos para resolver el problema de la indigencia, incluso con un crecimiento de la población. Tampoco hay que olvidar que, desde el final de la segunda guerra mundial hasta hoy, la población de la tierra ha crecido en cuatro mil millones y, en buena parte, este fenómeno se produce en países que han aparecido recientemente en el escenario internacional como nuevas potencias económicas, y han obtenido un rápido desarrollo precisamente gracias al elevado número de sus habitantes. Además, entre las naciones más avanzadas, las que tienen un mayor índice de natalidad disfrutan de mejor potencial para el desarrollo. En otros términos, la población se está confirmando como una riqueza y no como un factor de pobreza.

4. Otro aspecto que preocupa son las enfermedades pandémicas, como por ejemplo, la malaria, la tuberculosis y el sida que, en la medida en que afectan a los sectores productivos de la población, tienen una gran influencia en el deterioro de las condiciones generales del país. Los intentos de frenar las consecuencias de estas enfermedades en la población no siempre logran resultados significativos. Además, los países aquejados de dichas pandemias, a la hora de contrarrestarlas, sufren los chantajes de quienes condicionan las ayudas económicas a la puesta en práctica de políticas contrarias a la vida. Es difícil combatir sobre todo el sida, causa dramática de pobreza, si no se afrontan los problemas morales con los que está relacionada la difusión del virus. Es preciso, ante todo, emprender campañas que eduquen especialmente a los jóvenes a una sexualidad plenamente concorde con la dignidad de la persona; hay iniciativas en este sentido que ya han dado resultados significativos, haciendo disminuir la propagación del virus. Además, se requiere también que se pongan a disposición de las naciones pobres las medicinas y tratamientos necesarios; esto exige fomentar decididamente la investigación médica y las innovaciones terapéuticas, y aplicar con flexibilidad, cuando sea necesario, las reglas internacionales sobre la propiedad intelectual, con el fin de garantizar a todos la necesaria atención sanitaria de base.

${ }^{5}$ Cf. PABLO VI, Populorum progressio, 37; JUAN PABLO II, Sollicitudo rei socialis, 25. 
5. Un tercer aspecto en que se ha de poner atención en los programas de lucha contra la pobreza, y que muestra su intrínseca dimensión moral, es la pobreza de los niños. Cuando la pobreza afecta a una familia, los niños son las víctimas más vulnerables: casi la mitad de quienes viven en la pobreza absoluta son niños. Considerar la pobreza poniéndose de parte de los niños impulsa a estimar como prioritarios los objetivos que los conciernen más directamente como, por ejemplo, el cuidado de las madres, la tarea educativa, el acceso a las vacunas, a las curas médicas y al agua potable, la salvaguardia del medio ambiente y, sobre todo, el compromiso en la defensa de la familia y de la estabilidad de las relaciones en su interior. Cuando la familia se debilita, los daños recaen inevitablemente sobre los niños. Donde no se tutela la dignidad de la mujer y de la madre, los más afectados son principalmente los hijos.

6. Un cuarto aspecto que merece particular atención desde el punto de vista moral es la relación entre el desarme y el desarrollo. Es preocupante la magnitud global del gasto militar en la actualidad. Como ya he tenido ocasión de subrayar, "los ingentes recursos materiales y humanos empleados en gastos militares y en armamentos se sustraen a los proyectos de desarrollo de los pueblos, especialmente de los más pobres y necesitados de ayuda. Y esto va contra lo que afirma la misma Carta de las Naciones Unidas, que compromete a la comunidad internacional, y a los Estados en particular, a "promover el establecimiento y el mantenimiento de la paz y de la seguridad internacional con el mínimo dispendio de los recursos humanos y económicos mundiales en armamentos" (art. 26)"6.

Este estado de cosas, en vez de facilitar, entorpece seriamente la consecución de los grandes objetivos de desarrollo de la comunidad internacional. Además, un incremento excesivo del gasto militar corre el riesgo de acelerar la carrera de armamentos, que provoca bolsas de subdesarrollo y de desesperación, transformándose así, paradójicamente, en factor de inestabilidad, tensión y conflictos. Como afirmó sabiamente mi venerado predecesor Pablo Vl, "el desarrollo es el nuevo nombre de la paz ${ }^{\prime \prime}$. Por tanto, los Estados están llamados a una seria reflexión sobre los motivos más profundos de los conflictos, a menudo avivados por la injusticia, y a afrontarlos con una valiente autocrítica. Si se alcanzara una mejora de las rela-

- Carta al Cardenal Renato Rafael Martino con ocasión del Seminario Internacional organizado por el Consejo Pontificio para la Justicia y la Paz sobre el tema "Desarme, desarrollo y paz. Perspectivas para un desarme integral"( 10 de abril de 2008): L'Osservatore Romano, edición en lengua española (18 de abril de 2008), p. 3.

7 Populorum progressio, 87. 
ciones, sería posible reducir los gastos en armamentos. Los recursos ahorrados se podrían destinar a proyectos de desarrollo de las personas y de los pueblos más pobres y necesitados: los esfuerzos prodigados en este sentido son un compromiso por la paz dentro de la familia humana.

7. Un quinto aspecto de la lucha contra la pobreza material se refiere a la actual crisis alimentaria, que pone en peligro la satisfacción de las necesidades básicas. Esta crisis se caracteriza no tanto por la insuficiencia de alimentos, sino por las dificultades para obtenerlos y por fenómenos especulativos y, por tanto, por la falta de un entramado de instituciones políticas y económicas capaces de afrontar las necesidades y emergencias. La malnutrición puede provocar también graves daños psicofísicos a la población, privando a las personas de la energía necesaria para salir, sin una ayuda especial, de su estado de pobreza. Esto contribuye a ampliar la magnitud de las desigualdades, provocando reacciones que pueden llegar a ser violentas. Todos los datos sobre el crecimiento de la pobreza relativa en los últimos decenios indican un aumento de la diferencia entre ricos y pobres. Sin duda, las causas principales de este fenómeno son, por una parte, el cambio tecnológico, cuyos beneficios se concentran en el nivel más alto de la distribución de la renta y, por otra, la evolución de los precios de los productos industriales, que aumentan mucho más rápidamente que los precios de los productos agrícolas y de las materias primas que poseen los países más pobres. Resulta así que la mayor parte de la población de los países más pobres sufre una doble marginación, beneficios más bajos y precios más altos.

\section{Lucha contra la pobreza y solidaridad global}

8. Una de las vías maestras para construir la paz es una globalización que tienda a los intereses de la gran familia humana ${ }^{8}$. Sin embargo, para guiar la globalización se necesita una fuerte solidaridad global', tanto entre países ricos y países pobres, como dentro de cada país, aunque sea rico. Es preciso un "código ético común" ${ }^{10}$, cuyas normas no sean sólo fruto de acuerdos, sino que estén arraigadas

8 JuAN PABLo II, Centesimus annus, 58.

9 JUAN PABLo II, Discurso a las asociaciones cristianas de trabajadores italianos (27 de abril de 2002), n. 4: L'Osservatore Romano, edición en lengua española (10 de mayo de 2002), p. 10.

10 JuAn Pablo II, Discurso a la Asamblea plenaria de la Academia Pontificia de Ciencias sociales (27 de abril de 2001), n. 4: L'Osservatore Romano, edición en lengua española (11 de mayo de 2001), p. 4. 
en la ley natural inscrita por el Creador en la conciencia de todo ser humano (cf. Rm 2,14-15). Cada uno de nosotros ìno siente acaso en lo recóndito de su conciencia la llamada a dar su propia contribución al bien común y a la paz social? La globalización abate ciertas barreras, pero esto no significa que no se puedan construir otras nuevas; acerca los pueblos, pero la proximidad en el espacio y en el tiempo no crea de suyo las condiciones para una comunión verdadera y una auténtica paz. La marginación de los pobres del planeta sólo puede encontrar instrumentos válidos de emancipación en la globalización si todo hombre se siente personalmente herido por las injusticias que hay en el mundo y por las violaciones de los derechos humanos vinculadas a ellas. La lglesia, que es "signo e instrumento de la íntima unión con Dios y de la unidad de todo el género humano"11, continuará ofreciendo su aportación para que se superen las injusticias e incomprensiones, y se llegue a construir un mundo más pacífico y solidario.

9. En el campo del comercio internacional y de las transacciones financieras, se están produciendo procesos que permiten integrar positivamente las economías, contribuyendo a la mejora de las condiciones generales; pero existen también procesos en sentido opuesto, que dividen y marginan a los pueblos, creando peligrosas premisas para conflictos y guerras. En los decenios sucesivos a la segunda guerra mundial, el comercio internacional de bienes y servicios ha crecido con extraordinaria rapidez, con un dinamismo sin precedentes en la historia. Gran parte del comercio mundial se ha centrado en los países de antigua industrialización, a los que se han añadido de modo significativo muchos países emergentes, que han adquirido una cierta relevancia. Sin embargo, hay otros países de renta baja que siguen estando gravemente marginados respecto a los flujos comerciales. Su crecimiento se ha resentido por la rápida disminución de los precios de las materias primas registrada en las últimas décadas, que constituyen la casi totalidad de sus exportaciones. En estos países, la mayoría africanos, la dependencia de las exportaciones de las materias primas sigue siendo un fuerte factor de riesgo. Quisiera renovar un llamamiento para que todos los países tengan las mismas posibilidades de acceso al mercado mundial, evitando exclusiones y marginaciones

10. Se puede hacer una reflexión parecida sobre las finanzas, que atañe a uno de los aspectos principales del fenómeno de la globalización, gracias al desarrollo de la electrónica y a las políticas de liberalización de los flujos de dinero entre los diversos países. La función objetivamente más importante de las finanzas, el sostener a largo plazo la posibilidad de inversiones y, por tanto, el desarrollo, se

${ }^{11}$ Concilio Vaticano II, Const. dogm. Lumen gentium, 1. 
manifiesta hoy muy frágil: se resiente de los efectos negativos de un sistema de intercambios financieros -en el plano nacional y global-basado en una lógica a muy corto plazo, que busca el incremento del valor de las actividades financieras y se concentra en la gestión técnica de las diversas formas de riesgo. La reciente crisis demuestra también que la actividad financiera está guiada a veces por criterios meramente autorrefenciales, sin consideración del bien común a largo plazo. La reducción de los objetivos de los operadores financieros globales a un brevísimo plazo de tiempo reduce la capacidad de las finanzas para desempeñar su función de puente entre el presente y el futuro, con vistas a sostener la creación de nuevas oportunidades de producción y de trabajo a largo plazo. Una finanza restringida al corto o cortísimo plazo llega a ser peligrosa para todos, también para quien logra beneficiarse de ella durante las fases de euforia financiera ${ }^{12}$.

11. De todo esto se desprende que la lucha contra la pobreza requiere una cooperación tanto en el plano económico como en el jurídico que permita a la comunidad internacional, y en particular a los países pobres, descubrir y poner en práctica soluciones coordinadas para afrontar dichos problemas, estableciendo un marco jurídico eficaz para la economía. Exige también incentivos para crear instituciones eficientes y participativas, así como ayudas para luchar contra la criminalidad y promover una cultura de la legalidad. Por otro lado, es innegable que las políticas marcadamente asistencialistas están en el origen de muchos fracasos en la ayuda a los países pobres. Parece que, actualmente, el verdadero proyecto a medio y largo plazo sea el invertir en la formación de las personas y en desarrollar de manera integrada una cultura de la iniciativa. Si bien las actividades económicas necesitan un contexto favorable para su desarrollo, esto no significa que se deba distraer la atención de los problemas del beneficio. Aunque se haya subrayado oportunamente que el aumento de la renta per capita no puede ser el fin absoluto de la acción político-económica, no se ha de olvidar, sin embargo, que ésta representa un instrumento importante para alcanzar el objetivo de la lucha contra el hambre y la pobreza absoluta. Desde este punto de vista, no hay que hacerse ilusiones pensando que una política de pura redistribución de la riqueza existente resuelva el problema de manera definitiva. En efecto, el valor de la riqueza en una economía moderna depende de manera determinante de la capacidad de crear rédito presente y futuro. Por eso, la creación de valor resulta un vínculo ineludible, que se debe tener en cuenta si se quiere luchar de modo eficaz y duradero contra la pobreza material.

${ }^{12}$ Cf. Consejo Pontificio para la Justicia y la Paz, Compendio de la Doctrina social de la lglesia, 368. 
12. Finalmente, situar a los pobres en el primer puesto comporta que se les dé un espacio adecuado para una correcta lógica económica por parte de los agentes del mercado internacional, una correcta lógica política por parte de los responsables institucionales y una correcta lógica participativa capaz de valorizar la sociedad civil local e internacional. Los organismos internacionales mismos reconocen hoy la valía y la ventaja de las iniciativas económicas de la sociedad civil o de las administraciones locales para promover la emancipación y la inclusión en la sociedad de las capas de población que a menudo se encuentran por debajo del umbral de la pobreza extrema y a las que, al mismo tiempo, difícilmente pueden llegar las ayudas oficiales. La historia del desarrollo económico del siglo XX enseña cómo buenas políticas de desarrollo se han confiado a la responsabilidad de los hombres y a la creación de sinergias positivas entre mercados, sociedad civil y Estados. En particular, la sociedad civil asume un papel crucial en el proceso de desarrollo, ya que el desarrollo es esencialmente un fenómeno cultural y la cultura nace y se desarrolla en el ámbito de la sociedad civil ${ }^{13}$.

13. Como ya afirmó mi venerado predecesor Juan Pablo II, la globalización "se presenta con una marcada nota de ambivalencia"14 $y$, por tanto, ha de ser regida con prudente sabiduría. De esta sabiduría, forma parte el tener en cuenta en primer lugar las exigencias de los pobres de la tierra, superando el escándalo de la desproporción existente entre los problemas de la pobreza y las medidas que los hombres adoptan para afrontarlos. La desproporción es de orden cultural y político, así como espiritual y moral. En efecto, se limita a menudo a las causas superficiales e instrumentales de la pobreza, sin referirse a las que están en el corazón humano, como la avidez y la estrechez de miras. Los problemas del desarrollo, de las ayudas y de la cooperación internacional se afrontan a veces como meras cuestiones técnicas, que se agotan en establecer estructuras, poner a punto acuerdos sobre precios y cuotas, en asignar subvenciones anónimas, sin que las personas se involucren verdaderamente. En cambio, la lucha contra la pobreza necesita hombres y mujeres que vivan en profundidad la fraternidad y sean capaces de acompañar a las personas, familias y comunidades en el camino de un auténtico desarrollo humano.

${ }^{13}$ Cf. ibíd., 356.

${ }_{14}$ Discurso a empresarios y sindicatos de trabajadores (2 de mayo de 2000), n. 3: L'Osservatore Romano, edición en lengua española (5 de mayo de 2000), p. 7. 


\section{Conclusión}

14. En la encíclica Centesimus annus, Juan Pablo II advirtió sobre la necesidad de "abandonar una mentalidad que considera a los pobres - personas y puebloscomo un fardo o como molestos e importunos, ávidos de consumir lo que los otros han producido". "Los pobres -escribe- exigen el derecho de participar y gozar de los bienes materiales y de hacer fructificar su capacidad de trabajo, creando así un mundo más justo y más próspero para todos"15. En el mundo global actual, aparece con mayor claridad que solamente se construye la paz si se asegura la posibilidad de un crecimiento razonable. En efecto, las tergiversaciones de los sistemas injustos antes o después pasan factura a todos. Por tanto, únicamente la necedad puede inducir a construir una casa dorada, pero rodeada del desierto - la degradación. Por sí sola, la globalización es incapaz de construir la paz, más aún, genera en muchos casos divisiones y conflictos. La globalización pone de manifiesto más bien una necesidad: la de estar orientada hacia un objetivo de profunda solidaridad, que tienda al bien de todos y cada uno. En este sentido, hay que verla como una ocasión propicia para realizar algo importante en la lucha contra la pobreza y para poner a disposición de la justicia y la paz recursos hasta ahora impensables.

15. La Doctrina Social de la Iglesia se ha interesado siempre por los pobres. En tiempos de la encíclica Rerum novarum, éstos eran sobre todo los obreros de la nueva sociedad industrial; en el magisterio social de Pío XI, Pío XII, Juan XXIII, Pablo $\mathrm{VI}$ y Juan Pablo II se han detectado nuevas pobrezas a medida que el horizonte de la cuestión social se ampliaba, hasta adquirir dimensiones mundiales ${ }^{16}$. Esta ampliación de la cuestión social hacia la globalidad hay que considerarla no sólo en el sentido de una extensión cuantitativa, sino también como una profundización cualitativa en el hombre y en las necesidades de la familia humana. Por eso la Iglesia, a la vez que sigue con atención los actuales fenómenos de la globalización y su incidencia en las pobrezas humanas, señala nuevos aspectos de la cuestión social, no sólo en extensión, sino también en profundidad, en cuanto conciernen a la identidad del hombre y su relación con Dios. Son principios de la doctrina social que tienden a clarificar las relaciones entre pobreza y globalización, y a orientar la acción hacia la construcción de la paz. Entre estos principios conviene

15 Juan Pablo II, Centesimus annus, 28.

${ }^{16} \mathrm{Cf}$. PABLO VI, Populorum progressio, 3. 
recordar aquí, de modo particular, el "amor preferencial por los pobres"17, a la luz del primado de la caridad, atestiguado por toda la tradición cristiana, comenzando por la de la Iglesia primitiva (cf. Hch 4,32-36; 1 Co 16,1; 2 Co 8-9; Ga 2,10).

"Que se ciña cada cual a la parte que le corresponde", escribía León XIII en 1891, añadiendo: "Por lo que respecta a la Iglesia, nunca ni bajo ningún aspecto regateará su esfuerzo"18. Esta convicción acompaña también hoy el quehacer de la Iglesia para con los pobres, en los cuales contempla a Cristo ${ }^{19}$, sintiendo cómo resuena en su corazón el mandato del Príncipe de la paz a los Apóstoles: "Vos date illis manducare - dadles vosotros de comer" (Lc 9,13). Así pues, fiel a esta exhortación de su Señor, la comunidad cristiana no dejará de asegurar a toda la familia humana su apoyo a las iniciativas de una solidaridad creativa, no sólo para distribuir lo superfluo, sino cambiando "sobre todo los estilos de vida, los modelos de producción y de consumo, las estructuras consolidadas de poder que rigen hoy la sociedad" 20 . Por consiguiente, dirijo al comienzo de un año nuevo una calurosa invitación a cada discípulo de Cristo, así como a toda persona de buena voluntad, para que ensanche su corazón hacia las necesidades de los pobres, haciendo cuanto le sea concretamente posible para salir a su encuentro. En efecto, sigue siendo incontestablemente verdadero el axioma según el cual "combatir la pobreza es construir la paz".

Vaticano, 8 de diciembre de 2008

BENEDICTO XVI

\footnotetext{
17 Juan Pablo II, Sollicitudo rei socialis, 42; Cf. Id. Centesimus annus, 57.

${ }^{18}$ LEÓN XIII, Rerum novarum, 41.

${ }^{19}$ Cf. Juan Pablo Il, Centesimus annus, 58.

${ }^{20}$ lbíd.
} 